\title{
Albrecht Penck: Vorbereiter und Wegbereiter der NS-Lebensraumpolitik?
}

\author{
Hans Dietrich Schultz \\ Geographisches Institut, Humboldt-Universität zu Berlin, Unter den Linden 6, 10099 Berlin, Germany
}

Correspondence: Hans Dietrich Schultz (hans-dietrich.schultz@geo.hu-berlin.de)

Relevant dates: $\quad$ Published: 10 January 2018

How to cite: $\quad$ Schultz, H. D.: Albrecht Penck: Vorbereiter und Wegbereiter der NS-Lebensraumpolitik?, E\&G Quaternary Sci. J., 66, 115-129, https://doi.org/10.5194/egqsj-66-115-2018, 2018.

Kurzfassung: $\quad$ Albrecht Penck gehört zu den bedeutendsten Quartärforschern der ersten Hälfte des 20. Jahrhunderts, doch daneben gab es auch einen politisch-geographischen Penck, der nach 1945 lange Zeit von Fachvertretern ausgeblendet oder verharmlost wurde. Heute wird er mit seinem Konstrukt des Volks- und Kulturbodens der 1920er Jahren als derjenige betrachtet, der die völkische Wende der deutschen Geographie eingeleitet hat. Damit, so der Vorwurf, habe er der nationalsozialistischen Lebensraumpolitik im Osten Europas den Weg geebnet und sei zum Mittäter ihrer mörderischen Politik geworden. Der vorliegende Beitrag untersucht Pencks politisch-geographisches Weltbild und kommt bezüglich der Vorwürfe zu einem ambivalenten Urteil.

Abstract: $\quad$ Albrecht Penck was one of the eminent representatives of Quaternary research in the first half of the twentieth century. But apart from this, there was a political-geographical side to Penck, which, since 1945, has long been ignored or downplayed by geographers. Today, given his concept of Volksund Kulturboden, he is considered as having ushered in German geography the völkisch (ethnonationalistic) turn. Thus, critics say, he paved the way for Nazi Lebensraum policies and became an accomplice in the resulting crimes. The present contribution examines Penck's political-geographical worldview and reaches an ambivalent conclusion regarding the accusations.

\section{Der Tatvorwurf}

Der 52. Deutsche Geographentag 1999 in Hamburg begann mit einem Paukenschlag. Einen Tag vor seiner Eröffnung sorgte Michael Fahlbusch in der Rolle des Staatsanwaltes mit einem ganzseitigen Artikel in der Frankfurter Rundschau für Aufregung. Unter der provokanten Überschrift: „Die verlorene Ehre der deutschen Geographie" klagte er im Untertitel an: „Bis heute wird die Mittäterschaft der akademischen Väter am Völkermord der Nationalsozialisten verdrängt" (Fahlbusch, 1999a: S. 6). Penck war durch seine ,berüchtigte Karte des deutschen Volks- und Kulturbodens von 1925“ be- sonders prominent in dem Artikel vertreten. Diese wie unzählige andere Karten dieses Genres hätten nach dem verlorenen Weltkrieg der amtlichen deutschen Kulturpropaganda dazu gedient, die Forderung nach einer Revision der Grenzen „,wissenschaftlich““ zu untermauern. Mit dem Machtantritt der Nationalsozialisten 1933 hätten sich dann „Penck, Metz, Hassinger und Meynen am Ziel ihres politischen Strebens“" gesehen: „Sie kooperierten hinfort mit der SS, der NSDAP und den ,gleichgeschalteten' Reichsministerien. Sie bereiteten die Grundlagen für die deutsche Volksgruppenpolitik vor. Ihrer völkischen Logik zufolge sollten nur jene Völker den Status der Schutzwürdigkeit zugewiesen bekommen, die ,bo- 
denständig ' waren, Juden und Zigeuner erhielten diesen Status nicht. Sie wurden gemäß der Nürnberger Rassengesetze für vogelfrei erklärt" (S. 6).

Was immer und begründet an diesem provokanten Artikel und an den Ergebnissen der Forschungen Fahlbuschs (1999b) zu kritisieren war: Er hat eine überfällige Diskussion vorangebracht und weiterführende Arbeiten angestoßen, die gezeigt haben, dass die Volks- und Kulturbodenforschung nicht nur anschlussfähig an die Lebensraumideologie der Nationalsozialisten war, sondern viele ihrer Vertreter auch durch ihre Praktiken einer verbrecherischen Politik dienten.

Auf Penck bezogen hat von geographischer Seite Herb festgestellt, dass ,die Übereinstimmung“ der von ihm ,,postulierten Gebiete deutschen Kultureinflusses mit den Lebensraumvorstellungen der Nationalsozialisten bzw. den deutschen Eroberungen im Zweiten Weltkrieg (...) nicht zu übersehen“ (Herb, 2005: S. 190) sei. Etwas umständlicher, aber ähnlich konstatierte Jureit aus historischer Sicht, Pencks ,,als Fortschrittsnarrativ arrangierte Kulturbodentheorie" habe es ermöglicht, territoriale Ansprüche jenseits der aktuellen Besiedlungsverhältnisse und damit unabhängig von den Identitätsentwürfen der derzeitigen Bewohner zu rechtfertigen" (Jureit, 2012: S. 243). Mommsens Urteil, die Volks- und Kulturbodentheorie, die mit den Geographen und Penck als „Schlüsselfigur“ begonnen habe, habe ,ursprünglich mit dem Nationalsozialismus überhaupt nichts zu tun" (Mommsen, 1999: S. 2) gehabt, scheint sich damit erledigt zu haben, erst recht aber, in Penck einen der Großen zu sehen, von dem in der „Geschichte unseres Faches auch noch in einer fernen Zukunft mit ähnlicher Verehrung" (Sölch, 1946: S. 88) gesprochen werde wie von Alexander v. Humboldt, Carl Ritter und Ferdinand von Richthofen.

So scheint also kein Weg daran vorbeizuführen, auch Penck und seine Schule auf die Politik des NS-Regimes beziehen zu müssen und in seinen politisch-geographischen Arbeiten ein weiteres Beispiel für die „fließende Grenze zwischen Propaganda und Wissenschaftlichkeit" (Kost, 1988: S. 346) zu erkennen. Doch ist der staatsanwaltliche Zugriff, den auch viele Historiker für die Geschichtsschreibung des Nationalsozialismus präferieren, der einzig sinnvolle? Reicht es, auf der Basis ,,akribischer Quellenarbeit“ herausfinden zu wollen, ,was ein Individuum von den Verbrechen des Nationalsozialismus wusste, inwieweit der Einzelne sie vorbereitete und inwieweit man ihm Verantwortung oder Schuld zuschreiben kann“, um ihn ,als ,Vordenker der Vernichtung “ (...) oder zumindest als Vordenker des Faschismus" zu entlarven (Etzemüller, 2004: S. 27)?

„Zweifellos“, so Etzemüller, selbst Historiker, sei ein solcher Ansatz „notwendig“ - „Ohne Individuen, deren Intentionen man kausal auf die Verbrechen des NS bezöge, könnte man eine Geschichte des Nationalsozialismus gar nicht schreiben" -, doch ergäben sich zwei Probleme: Erstens werde bei posthumen Schulduntersuchungen leicht ,die Unschuldsvermutung von vornherein“ ausgeblendet, um „methodische Ansätze mit moralischen Argumenten“ (Etzemül- ler, 2004: S. 27) zu bekämpfen, zweitens verdecke die nachträgliche Einstufung von Individuen als Schuldige oder (lediglich) Verführte mehr, als dass sie dazu beitrage, die eigentlich wichtige Frage beantworten zu helfen, ,wie der Nationalsozialismus sich entfalten konnte" (S. 28). Besser sei es darum, folgende drei Analyseebenen zu unterscheiden: (1) die Ebene des ,Wollens“, der man Schuld zuordnen könne, (2) die Ebene des „Nichtsehen-Wollens“, die die Folge von Verdrängung sei, und (3) die Ebene des „NichtsehenKönnens", die Praktiken beinhalte, die im Sinne des Regimes und seiner Verbrechen Effekte gezeigt hätten, die die Beteiligten „tatsächlich nicht sehen konnten“ (S. 31, Herv. HDS) ${ }^{1}$. Gerade den letzten Punkt hält er für besonders wichtig, denn mit ihm lasse sich beobachten, ,wie von Betroffenen Handlungen in ein kognitives System eingefügt wurden, so daß diese Handlungen legitim erschienen, während die Effekte“" (S. 31) den Nationalsozialisten zugerechnet werden konnten.

Im Folgenden werde ich auf der Basis von Pencks Publikationen seine politisch-geographischen Vorstellungen in ihren Hauptzügen skizzieren und dazu einen kolonialpolitischen, einen politisch-geographischen und einen ethnopolitischen Penck unterscheiden. Im abschließenden Urteil orientiere ich mich an Etzemüller, speziell an seinem letzten Punkt.

\section{Der kolonialpolitische Penck}

Den kolonialpolitischen Penck halte ich kurz. Penck trat entschieden für deutsche Kolonien ein und brachte stets folgende drei Argumente vor: Erstens bedeuteten Kolonien schon durch den Flächenzuwachs mehr Macht für das Mutterland, zweitens könnten sie überschüssige Bevölkerung aufnehmen, die so dem eigenen Volke nicht verloren gehe, und drittens böten die fruchtbaren Tropen die Lösung der Ernährungsfrage der Menschheit.

Die Kolonien gingen im Ersten Weltkrieg rasch verloren, doch tröstete sich Penck damit, dass die Gewinne in Belgien und Nordfrankreich bei weitem die kolonialen Verluste überwögen. Der bisherige Kriegsverlauf, Stand 1917, habe Deutschlands „kontinentale Stellung in Europa“ gestärkt und werde es ,ermöglichen, sie zurückzuverlangen mit einer ansehnlichen Zugabe bisherigen französischen und belgischen Kolonialbesitzes“ (Penck, 1915a: S. 19f.). In seiner Antrittsrede als Rektor der Berliner Universität forderte Penck ,einen Kolonialbesitz (...), groß und reich genug, um uns mit den unentbehrlich gewordenen Rohstoffen der Tropen zu versehen“ (Penck, 1917: S. 31).

Auch nach dem Verlust der Kolonien propagierte Penck unermüdlich die Tropen als „Länder der Zukunft“. Allerdings nicht für massenhafte Siedlung! Doch böten sie den Weißen genügend Gelegenheit, sich ,,als Pflanzer, Ingenieure, Kaufleute oder Beamte“ zu betätigen, ,nicht als Herren über Sklaven, sondern als Vormünder über Unmündi-

\footnotetext{
${ }^{1}$ Alle folgenden Kursivstellen innerhalb von Zitaten sind Hervorhebungen im Original.
} 
ge" (Penck, 1936: S. 263). Deutschland als Kolonialmacht auszuschließen, sei ein Riesenfehler; denn man brauche den Einstrom weißen Blutes, ohne den die Macht der Weißen über die Farbigen nicht aufrechterhalten werden könne. AuBerdem waren in Pencks Augen Kolonien ein hervorragendes Erziehungsprogramm. Befreit von der Enge des eigenen Raumes, würden hier deutsche Menschen „zu Führern“ erzogen werden können, ,prächtige Menschen“ (Penck, 1936: S. 263), wie man gesehen habe.

Auffällig ist, dass Penck bei der Forderung nach Rückgabe der Kolonien immer wieder die Trommel der Menschheit rührte, doch das war bei den Kolonialbefürwortern üblich, denen es im Kern darum ging, die Herrschaft der Weißen als Dienst am Fortschritt der Menschheit zu rechtfertigen und aufrechtzuerhalten.

\section{Der politisch-geographische (geo-politische) Penck}

Um den politisch-geographischen Penck zu verstehen, muss man wissen, dass die Geographie sich seinerzeit als Länderkunde verstand, die angesichts politisch unruhiger Zeiten um 1800 als Alternative zur Staatenkunde aufgekommen war und sich nach längerem Hin und Her um 1900 soweit durchgesetzt hatte, dass sie als die Kernaufgabe der Geographie galt. Parallel dazu hatte sich ebenfalls durchgesetzt, dass die Geographie zwar eine Brücke zu den sogenannten Geisteswissenschaften bilde, indem sie Natur und Kultur miteinander verschmelze, aber dies von einer naturwissenschaftlichen Grundposition heraus. Geographisch zu denken, bedeutete, den Menschen (das Gesellschaftliche, das Wirtschaftliche und das Politische) primär in seiner Abhängigkeit von der Natur der Länder zu betrachten, wofür (Wahrscheinlichkeits-) Gesetze gefunden werden sollten. Länder waren die Teile der Erdoberfläche, die sich durch ihre Eigenart als Natur- und Kulturräume charakteristisch voneinander unterschieden.

Der Dauerstreit, der sich mit der Umstellung von Staaten auf Länder für die Geographie ergab, war das Verhältnis dieser beiden Raumbegriffe zueinander, wobei die Spannweite der Positionen von der Annahme einer Deckungstendenz bis zur Behauptung einer völligen Unabhängigkeit der beiden Kategorien reichte. Dazu kamen noch die Siedlungsräume der Völker, deren Beziehung zu den beiden anderen den Geographen ebenfalls interessierte. Zwar erkannte man schon in der ersten Hälfte des 19. Jahrhunderts, dass Länder meist allmählich ineinander übergingen, und sprach von Grenzräumen und -säumen, dennoch blieb der Begriff der ,natürlichen Grenzen“ " im Sinne mehr oder weniger linearer Marken, einmal in die Welt gesetzt, ein Dauerbrenner geographischer Diskussionen.

Penck beschäftigte sich in seinen Publikationen mit solchen Fragen intensiv erst seit dem Ersten Weltkrieg. Zunächst, 1915, versuchte er zu klären, welche meridionale
Gliederung Europa jenseits der Ebene der Länder aufwies, da er davon ausging, ,daß die geographische Lage der Länder die gemeinsamen Interessen der Völker in weitem Umfange“ bestimme. Er nannte die drei Streifen Vorder-, Zwischenund Hintereuropa und prognostizierte für Zwischeneuropa, dass es als „ein eng zusammengeschlossenes“ Gebiet, ,das vom Weißen Meer bis zum Bosporus" reiche, ,das feste Rückgrat für Europa abgeben" (Penck, 1915b: S. 40) werde. Anhand von Diagonalen, die die Ecken Europas miteinander verbanden und deren Mitten sich nahe der Quelle der Memel trafen, veranschaulichte Penck, dass derzeit allerdings noch Russland weit nach Mitteleuropa hineinreiche. Es hatte damit aus Pencks Sicht jene Grenzen missachtet, welche die Natur ihm angewiesen hatte, und sollte daher auf sein natürliches Gebiet, Hintereuropa, zurückgedrängt werden. Ein eindringlicher Blick auf das Land zeigte Penck die natürlichen „Nähte“, ,an welchen das Zarenreich nur oberflächlich zusammengeschweißt“" sei und ,längs derer es leicht wieder auseinanderfallen“" (Penck, 1918a: S. 40) könne.

Zugearbeitet hatte ihm diesbezüglich sein Schüler Rudnyćkyj, der nachweisen zu können glaubte, dass Osteuropa keineswegs, wie allgemein angenommen, ein gliederungsfreier, homogener Naturraum sei, sondern morphologische, hydrographische, klimatische, pedologische und pflanzengeographische Unterschiede (Rudnyćkyj, 1916: S. 5) aufweise, die sich in natürlichen Einheiten niederschlügen, die ihrerseits eine große Einheitlichkeit zeigten, darunter Baltland, Weißrußland und die Ukraina. Penck ließ es sich nicht nehmen, in einem langen Artikel die Existenz eines selbständigen ukrainischen Staates geographisch zu begründen und Mitteleuropa anzuschließen: ,natürliche Grenzen würden einen solchen Staat von Rußland scheiden" (Penck, 1916a: S. 477).

Auch Polen, das Penck nur als ein loses Anhängsel an das Zarenreich betrachtete, galt ihm als echtes Stück des „germanischen Mitteleuropas“, da es gleich diesem einen Dreiklang der morphologischen Großformen aufweise, nämlich „Karpathen, vorgelagerte Landschwelle und Tiefland“ (Penck, 1918b: S. 127). Den Begriff des „Dreiklangs“ übernahm er von Partsch, der ihn 1904, was damals noch als ungewöhnlich galt, als Charakteristikum für ,,das weite Ländergebiet zwischen Ostende und Genf, Memel und Burgas“ bestimmt hatte, das „den zentralen Kern der europäischen Staatenfamilie“ (Partsch, 1904: S. 5) darstelle. Bis auf wenige Stellen würden die politischen Grenzen dieser Staatengruppe von den natürlichen ,selten weit entfernt“ bleiben, nur mit Deutsch-Lothringen, Teilen Bulgariens und Galiziens „über die natürlichen Schranken“ (S. 5) hinausgreifen, mit der jütischen Halbinsel und Polen hingegen dahinter zurückbleiben. Über Partsch hinausgehend, setzte Penck weiter östlich noch ein „,sarmatisches Mitteleuropa“ (Penck, 1918b: S. 129) an. Außerdem schaltete er zwischen Hintereuropa und Zwischeneuropa einen breiten Grenzsaum ein, den er nach dem Zug der schwedischen Waräger als ,warägischen Grenzsaum“ bezeichnete. Dieser ziehe vom Finnischen Golf 
an den Pripjetsümpfen vorbei bis zum Asowschen Meer und trenne „das plumpe kontinentale von dem mehr gegliederten Europa" (S. 127).

Eine besondere Herausforderung war für Penck Österreich-Ungarn. Im Gegensatz zu zahlreichen reichsdeutschen Kollegen, die diesen Staat als besonders ungeographisches Gebilde einstuften, das vor dem Zusammenbruch stehe, verteidigte Penck, der zwei Jahrzehnte in Wien gelehrt hatte, ihn entschieden als naturgewollt. So wehrte er Italiens Ansprüche auf Süd-Tirol, die es mit der Wasserscheidengrenze begründete, mit Verweis darauf $a b$, dass das „Paßland“ Tirol „ein Ganzes, eine geographische Einheit" (Penck, 1916b: S. 47) sei, die über die Wasserscheide hinweggehe und noch nicht einmal völlig politisch ausgefüllt werde. Die „einende Kraft“ der geographischen Züge des Landes sei ,eine so starke, daß, wie in anderen Paßländern, Menschen verschiedener Zunge in einem Lande zusammengefaßt worden“ (S. 44) seien. Den Gesamtstaat Österreich-Ungarn verteidigte Penck mit dem Argument, er sei ,unter dem Zwange geographischer Verhältnisse“ (Penck, 1915b: S. 18) zusammengewachsen. Dieser Staat sei „kein Erobererstaat, zusammengeschweißt durch den eisernen Willen eines Herrschers“, aber auch „kein Nationalstaat, sondern ein Agglomerat von Völkern“, das auf der besonderen Natur des Landes beruhe: „Ein solcher, durch die Natur zusammengehaltener Staat braucht Naturgrenzen“ (Penck, 1916b: S. 75). Das Wiener Becken wirke dabei als geographischer Anziehungspunkt für die umliegenden Landschaften; und sogar hinter dem Zweibund steckte laut Penck „das Nachwirken starker natürlicher Ursachen“ (Penck, 1915b: S. 20). Er war für ihn keine zufällige Erscheinung.

Ausführlicher theoretisch äußerte sich Penck (mit erkennbarer Anlehnung an Ratzels Politische Geographie) zur Frage der ,natürlichen Grenzen“, die ,eine der schwierigsten der politischen Geographie“ (Penck, 1916b: S. 8) sei, in seiner Antrittsrede als Rektor der Berliner Universität im Herbst 1917. Solche Grenzen, meinte er, seien nicht schon per se gute Grenzen, sie böten „lediglich die Idee, den Leitsatz, zur Ziehung einer solchen Grenze“, seien ,,aber vielfach nur ein leeres Schlagwort zur Rechtfertigung von Gebietsansprüchen“; kein zivilisierter Staat begnüge ,sich heute mit bloBen natürlichen Grenzen“, erst ihre „Vermarkung“ verleihe ihnen „Eindeutigkeit“ (Penck, 1917: S. 8). Wähle ein Staat eine natürliche Grenze zur Vermarkung aus, dann sei sie nur dann auch eine gute, eine „organische" Grenze, wenn sie zur „Natur“ dieses Staates passe, d.h., ,,aus dem Staate heraus verstanden" werde; doch selbst im Falle von natürlichen Grenzen mit einer ,solch starken Wirkung“ wie im Falle der Schweiz würde ein „,noch so starker Bürgersinn“ (S. 14f.) gegenüber einem stärkeren Nachbarn nichts ausrichten können. Allerdings könne ,die Kraft geographischer Verhältnisse" (S. 15) bei der Staatenbildung sich nur dann begünstigend auswirken, wenn deren Größe zeitgemäss sei. Wüchsen die Staaten flächenmäßig, so verlören einst zu ihnen passende Räume und organische natürliche Grenzen ihre Funktion.
Penck beruhigte aber seine „Volksgenossen“ in Österreich und der Schweiz, sie nicht als ,,unerlöste Brüder““ (S. 17) zu betrachten und in Grenzvorsprüngen eher „Gebiete der Berührung als solche der Reibung" zu sehen.

Den Inhalt des Staates sah Penck ,,in einer unlösbaren Verknüpfung von Land und Volk“: ,Aus dem Volke fließen die immer sich erneuernden staatsbildenden Kräfte, im Lande wurzeln die staatserhaltenden Faktoren. Das Land ist der Boden, auf dem der Staat wurzelt und gedeiht“" (Penck, 1917: S. 18). Pencks politisches Ideal war erfüllt, wenn ein ,weitblickender Herrscher“ die Entwicklung eines Staates ,,behutsam auf einen bestimmten Lebensraum" (S. 18) lenkte. Dieser sollte so groß sein, dass er ,die wirtschaftlichen Grundlagen für das staatliche Leben" bot und den Zusammenhalt des Staates sowie seine Sicherheit begünstigte. Reine Erobererstaaten würden dagegen rasch wieder zerfallen. Neben einem Herrscherwillen könne aber auch der „Volkswille“, wie das Beispiel Italiens zeige, ,,auf nationaler Grundlage einen scharf ausgesprochenen Lebensraum gewinnen", doch wolle die italienische Nationalbewegung sich Länder aneignen, „,die außerhalb seiner durch das Meer und die Alpen gezogenen organischen Grenze“ (S. 18f.) lägen.

In einem anderen Teil Europas, dem Gebiet ,zwischen der östlichen Ostsee und dem östlichen Mittelmeere“, lasse der Boden zwar auch ,einzelne Lebensräume“ erkennen, doch zeige „die Völkerkarte ein buntscheckiges Bild“, weil die „Völker und Nationen“ sich hier nicht ,im geringsten“ um diese Lebensräume kümmern würden. Hier seien Nationalstaaten, ,die sich mit bestimmten Lebensräumen decken, unmöglich“(Penck, 1917: S. 19).

Flüsse galten Penck auf keinen Fall als ,naturgemäße“ politische Grenzen, mochten sie auch aus militärischer Sicht guten Schutz bieten und sich „,bei der Aufteilung eines Landes in Grundeigentum“ eignen: „Große Ströme bilden mehr das Gerüst von Staaten“ (Penck, 1917: S. 24). Den „beste[n] Rahmen für einen Lebensraum“ sah er von Meeresküsten, hohen Gebirgen, Wüsten und Sümpfen gezogen. Solche wenngleich breiten Übergangsräume gäben ,den Staaten naturgemäße, organische Grenzen“" (S. 23). Daneben gebe es Lebensräume, deren Grenzen ,unbestimmt" seien oder „gänzlich“ fehlten, so daß die Staaten, die in sie hineingewachsen seien, nicht durch ,naturgemäße organische Grenzen“ geschieden werden könnten. Hier sorge das Machtund Kräfteverhältnis im Hin und Her um eine immer deutlicher erkennbare Mittellinie herum allmählich für einen Ausgleich, der den Lebensbedürfnissen der Staaten gerecht werde. Für Penck entsprach dies Vorgängen, wie sie auch im Pflanzen- und Tierreich abliefen, hatte also für ihn ,naturwissenschaftliche Bedeutung“ (S. 24).

Hatte Penck 1917 noch auf eine Präzisierung seines Lebensraum-Begriffs verzichtet, so holte er dies 1926 nach. Der Begriff umfasse eine natürliche „Formengesellschaft“ von „Landschaften“, die sich mit ihrer räumlichen „Gestalt“ deutlich von einer anders gearteten Umgebung abhöben. Man dürfe sie allerdings nicht so missverstehen, als seien sie 
jeweils für die Aufnahme eines bestimmten Volkes vorgesehen. Die staatenbildenden Kräfte des Landes stellten einzig mit den „,natürlichen Gegebenheiten“ das Potenzial für eine Staatenbildung dar. Das Angebot der Natur konnten somit verschiedene Völker nutzen und zu ihrem Lebensraum umgestalten. Vorgefundene Bevölkerungen würden dabei, oft gewaltsam, assimiliert. Teleologische Spekulationen lehnte Penck entschieden ab. „Das Zusammenfallen von geographischen Gestalten mit Volks- und Staatenräumen“" spiegele keine ,natürliche Zweckbestimmung der Länder“ (Penck, 1926: S. 81). Nicht die Erdoberfläche schaffe sich den Staat, sondern der Wille eines Einzelnen oder ganzer Völker, wie Penck ähnlich schon 1916b für die österreichische Alpengrenze und 1917 in seiner Rektoratsrede betont hatte.

Doch obwohl Penck auf den ersten Blick die Staatenbildung allein vom Willen der Menschen abhängig zu machen scheint, nahm er zugleich an, dass dieser Wille „bei der großen Masse“ des Volkes „unter stiller Beeinflussung von Seiten ihrer Umgebung“ stehe. „Harmonische Landschaften“ würden „das Gefühl der Zusammengehörigkeit und den Wunsch des Zusammenschlusses" zeitigen. Das war für Penck die geistige Macht des Bodens, die schließlich „,zu einer dauernd wirkenden, Staaten bildenden Kraft" führe, die „dem Willen der Einzelnen wie der zündenden Macht einer Idee“ (Penck, 1926: S. 81) trotze. Niemand konnte sich demzufolge über die Gegebenheiten der Natur überheben!

$\mathrm{Zu}$ Ende gedacht, müsste das dazu führen, dass ein willkürlich an einen Staat angeschlossenes Stück Natur, das nicht zum Lebensraum dieses Staates passte, disharmonische Spannungen unter seinen Bewohnern aufkommen lassen würde. Ein solcher natürlicher Unruheherd durfte nicht bestehen bleiben; und tatsächlich befand Penck (wie unter Länderkundlern gang und gäbe): „Auf die Dauer ist die Natur stärker als der Mensch“ (Penck, 1926: S. 81). So bleibt als Credo des Geographen: Der Mensch beherrscht die Natur nur scheinbar, tatsächlich beherrscht sie ihn! Denn was immer er tat, Bestand hatte auf lange Sicht nur, was sich ihren Bedingungen fügte. Also doch politisch-geographische Teleologie?

\section{Der Sonderfall Deutschland}

Bleibt zum politisch-geographischen Penck noch seine Sicht auf Deutschland übrig, das unter Geographen als Sonderfall Europas galt. Schon in seiner Rektoratsrede beklagte er, „daß jahrhundertelang keine zielbewußte Hand“ sein „Hineinwachsen in einen bestimmen Lebensraum" gelenkt habe, wie deutlich daran sichtbar werde, ,„daß ihm Quellgebiet und Mündungsgebiet des Rheines fehlen“(Penck, 1917: S. 24).

Erstmals war Penck in den 1880er Jahren mit der Frage nach Deutschland als einem geographischen Land durch seine Mitarbeit an der von Alfred Kirchhoff herausgegebenen Länderkunde von Europa konfrontiert worden. Penck hatte den Band zum Deutschen Reich übernommen, den eine von Kirchhoff verfasste länderkundlichen Skizze zu Europa einleitete, die davon ausging, dass sich ,in den Staatengrenzen Europas (...) vorwiegend die Umriß- und Bodenbaugliederung" (Kirchhoff, 1887: S. 87) des Erdteils abspiegele. Pencks Teil begann jedoch nicht sofort mit dem Deutschen Reich, sondern einer physikalischen Skizze von „Mitteleuropa“, mit der ausgedrückt werden sollte, dass das Reich ,innerhalb natürlicher Grenzen, innerhalb ein und desselben von der Natur einheitlich charakterisierten Gebietes" lag, dieses jedoch nicht vollständig ausfüllte, da ihm ,äußerst wichtige Glieder Mitteleuropas, wie das böhmische Becken und vor allem die Rheinmündungen“ (Penck, 1887: S. 133f.) fehlten. Dennoch hielt es Penck für unbestreitbar, dass es „,nicht bloß ein nationaler, sondern auch ein geographischer Begriff" (S. 134) sei.

Diese Konzession musste er machen, weil Kirchhoff entgegen aller bisherigen Fachtradition und auch seiner eigenen früheren Auffassung inzwischen die kleindeutsche Reichsgründung als geographisch begründet und somit politisch berechtigt vertrat, was bei seinen großdeutsch denkenden Kollegen auf heftigen Widerstand stieß. Für sich selbst löste Kirchhoff den Widerspruch zu seiner früheren Position, indem er auch ein größeres Deutschland für geographisch möglich erklärte, doch habe die historische Entwicklung dazu geführt, dass sich an der Peripherie dieses Gebietes auf der Basis spezieller natürlicher Verhältnisse politische Sonderinteressen entwickelt hätten, die eine eigene Staatenbildung zur Folge gehabt hätten. „Mitteleuropa“ war bei Kirchhoff somit Ersatzbezeichnung für das ältere natürliche Deutschland der Geographen, das auch die Niederlande, Belgien, Luxemburg, die Schweiz und Österreich einschloss und manchmal noch Dänemark. Kirchhoffs Deutschlandversion kam Penck allerdings insofern entgegen, als ihm, dem in Österreich Lehrenden, andernfalls eine geographische Rechtfertigung Österreich-Ungarns verbaut gewesen wäre. Freilich fällt auf, dass er den eigenständigen Landcharakter des Deutschen Reiches einfach hinnahm, ohne ihn eingehender zu begründen.

Nach dem Ersten Weltkrieg ergab sich für Penck eine neue Situation, nachdem Österreich-Ungarn, dem er im Krieg eine natürliche Legitimation beschafft hatte, von der Landkarte verschwunden war. Sein oben schon im Zusammenhang mit dem Lebensraum-Begriff zitierter Aufsatz Deutschland als geographische Gestalt von 1926 beginnt mit dem Postulat: „Deutschland ist für uns eine natürliche Einheit und nicht bloß ein politischer Begriff. Ein solcher ist das Deutsche Reich“ (Penck, 1926: S. 72). Deutschland sei aber auch nicht „das Land, in dem nur deutsch gesprochen“ werde, denn es greife ,,von altersher über den deutschen Sprachboden hinweg“ und decke sich „nicht mit diesem“; vielmehr sei Deutschland, was seit Jahren gelte, ,ein bestimmter Teil der Erdoberfläche mit charakteristischen Eigenheiten, von eigener Gestalt“ (S. 73), so wie dies auch für andere Länder gelte. Wie ein Teppich verschiedene Muster biete, so höben sich in Europa bestimmte Ländergestalten voneinander $a b$. Um sie 
zu erkennen, dürfe man sich jedoch nicht an äußere natürliche Marken, z.B. Wasserscheiden, halten, vielmehr komme es auf ,ihren geographischen Inhalt“ (S. 74) an. Der Geograph, der sie „sehen“ wolle, müsse sich an „,die neuere physiologische Psychologie“" halten, um sie methodisch als ,ganze Formengesellschaften“ wahrnehmen zu können, die ,,morphologisch als Landschaften bezeichnet worden“" (S. 74) seien. Penck verwies dabei auf sich selbst und seine Morphologie der Erdoberfläche von 1894 (Penck, 1894).

Die Grenzfrage war für Penck damit aber keineswegs bedeutungslos geworden, auch Gestalten brauchten Grenzen, nur seien sie im Falle Deutschlands trotz klarer Eigenart seiner Gestalt „wenig deutlich“ (Penck, 1926: S. 79). Was Penck bot, war jedoch seit der ersten Hälfte des 19. Jahrhunderts altbekannt. Nachdem Österreich-Ungarn nicht mehr existierte, umgrenzte er sein natürliches Deutschland jetzt unbeschwert in deutlicher Anlehnung an die Territorialverhältnisse des mittelalterlichen Alten Reiches und begann mit der Straße von Calais. Den weiteren Verlauf markieren, wie schon im frühen 19. Jahrhundert gängig, Ardennen, Vogesen und der Schweizer Jura. Im Südwesten wird die Grenze zunächst vom Alpenkamm getragen, dann aber greift sie darüber hinweg, um „,die beiden Längstalzüge innerhalb des Gebirges“ (S. 79) ganz zu umfassen. Ein Großteil der Alpen ist nun geographisches Deutschland. Zwischen Donau und Oder lieferten Penck ,die Höhen einzelner Karpathenstücke (...) eine gute Grenze gegen das pannonische Becken“ (S. 79), doch im Osten suchte er, wie andere vor ihm, vergeblich nach natürlichen Anhaltspunkten für eine Begrenzung. Während frühere Versuche sich darauf konzentrierten, zwischen Oder und Weichsel doch noch schwache Andeutungen zu entdecken, die als natürliche Grenzen taugten, fand Penck erst in den Pripjetsümpfen eine eindeutige Grenzmarke, die ihm jedoch zu weit weg lag, um ernsthaft als natürliche Begrenzung Deutschlands in Betracht zu kommen, ja, Penck spielte nicht einmal mit dem Gedanken, sie anzupeilen. Vielmehr schob er, nachdem im Ersten Weltkrieg klar wurde, dass Polen eine staatliche Wiedergeburt erleben würde, dieses als eine weitere geographische Landgestalt zwischen Deutschland und Russland ein.

Anfangs, 1918, hatte Penck (s.o.) Polen noch mit Partsch in den mitteleuropäischen Dreiklang einbezogen, jetzt, nachdem sich die politische Landkarte Europas auf dem Boden der Mittelmächte dramatisch geändert hatte, erkannte er für Polen nur noch einen Zweiklang, der sich vom ,eigenartigen und sehr charakteristischen" (Penck, 1926: S. 79) deutschen Dreiklang deutlich abhebe. Hatte Partsch einst unter Einschluss der mittleren Weichsel formuliert: „Der Dreiklang Alpen, Mittelgebirge, Tiefland beherrscht die Symphonie des mitteleuropäischen Länderbildes. Wo einer seiner Töne ausklingt, ist Mitteleuropa zu Ende“ (Partsch, 1904: S. 4), so dekretierte Penck jetzt: „Diese Sinfonie ist nur für ihn [den deutschen Boden] charakteristisch" (Penck, 1926: S. 77). Polen falle aus dem Dreiklang heraus, weil es über kein zusammenhängendes Hochgebirge verfüge und auch sein Mittelge- birge sich in deutlich anderer Gestalt zeige als das deutsche. Letzteres bestehe aus einem Gebirgsgürtel mit zwei Beckenlandschaften, während dem polnischen beides fehle (zur polnischen Sicht vgl. Briesewitz, 2014).

Eines der beiden großen süddeutschen Becken und damit zugleich des geographischen Deutschlands war für Penck das Böhmische Becken, das er früher, solange ÖsterreichUngarn noch existierte, durch die geographischen Verhältnisse auf den Mittelpunkt Wien hingezwungen sah. Während er 1887 befand: „Im Böhmischen Becken verschmelzen Umwallung und Einsenkung zu einem Massive und verhalten sich völlig einheitlich“ (Penck, 1887: S. 206), argumentierte er nach dem Krieg, dass die gebirgige Umwallung Böhmens und sein meist durch Hochland ausgefülltes Becken zwei geographisch verschiedene Räume seien. Deutlich hebe sich „Deutsch-Böhmen auch geographisch gegenüber Tschechisch-Böhmen hervor" (Penck, 1918/19: S. 177). Es sei nicht wahr, ,daß der tschechische Staat die historische Grenze Böhmens als natürlich Grenze brauchte" (S. 178).

Besonders heftig kritisierte Penck seinen Mitstreiter in Deutschtumsfragen, Wilhelm Volz, der sich besonders im Kampf um Oberschlesien hervorgetan hatte. Er warf ihm „politische Kurzsichtigkeit“" und ein „Verkennen von Tatsächlichem“ (Penck, 1930/31: S. 514) vor, womit Volz' Begriff des ,natürlichen Deutschlands“ gemeint war. Volz ging nämlich davon aus, dass die Alpen als eine eigenständige natürliche Landschaft „neben“ dem geographischen resp. natürlichem Deutschland zu gelten hätten, das nur bis zum Alpenrand reiche, wenngleich auch die Alpen überwiegend „deutsches Siedlungsland und deutscher Volksboden“ seien; das deutsche Volk bewohne eben, ,zwei natürliche Landschaften, seiner Menschenzahl entsprechend" (Volz, 1927: S. 12). Penck rügte dies. Würde der Alpenraum nicht zum natürlichen Deutschland gehören, würde den dort lebenden Deutschen ,die geographische Grundlage ihres Daseins entzogen" (Penck, 1930/31: S. 514).

Wie die angeführten Beispiele zeigen, flüchtete Penck keineswegs aus der Länderkunde; ein Paradigmen-Bruch, d.h. ein Wechsel von einem geozentrischen zu einem ethnozentrischen Territorialkonzept, wie Herb (2005: S. 188) meint, findet mit ihm nicht statt. Wenn Penck bedauert, dass das Deutsche Reich „,seine Ländergestalt“ „,am wenigsten“ erfülle, während Frankreich dabei sei, die Deutschen ,außerhalb seiner Ländergestalt" (Penck, 1926: S. 81) zu französisieren, so unterstreicht dies nur, dass auch er daran festhielt, dass sich Länder („Lebensräume“) und Staaten möglichst decken sollten. Allerdings seien die Einwirkungen des Menschen auf den Boden „viel stärker" als umgekehrt, da der Einfluß des Landes auf seine Bewohner „,nur sehr langsam zur Geltung“ komme und ,nicht einmal in langer Zeit [die] Stammesunterschiede verwischt" (Penck, 1930/31: S. 514) habe. Aber wirkungslos war er auch aus Pencks Sicht nicht. 


\section{Der ethnopolitische Penck}

Der ethnopolitische Penck ist an den Doppelbegriff des „,deutschen Volks- und Kulturbodens“ geknüpft. Der Historiker Hermann Aubin stellte 1937 fest: „Albrecht Penck prägte mit dem Wort vom deutschen Volksboden den anschaulichen und inhaltsreichen Begriff der Fläche, welche die Deutschen in Europa innehaben. (...) Penck lehrte weiter, über den deutschen Volksboden hinaus den deutschen Kulturboden zu erkennen“"(Aubin, 1937: S. 45).

Einzeln kommen beide Bestandteile des Doppelbegriffs beiläufig schon in der ersten Hälfte des 19. Jahrhunderts vor, auch in der Geographie (Schultz, 2011: S. 119ff.). Bei Mendelssohn heißt es 1836 bei einem Vergleich von Russland mit Nord-Amerika: „Das eine Volk aus der Barbarei so eben auftauchend; das andre durch Verpflanzung aus altem Kulturboden in eine neue Erde verjüngt" (Mendelssohn, 1836: S. 474). In Roons „Physischer Geographie“ werden „,die zusammenhängenden Flächen des Kulturbodens" im nordöstlichen Europa erwähnt, „,namentlich die Gebiete um die Kama und mittlere Wolga (...), die Landschaft um den mittleren Dnjepr, um die mittlere Weichsel etc.“, die „vermöge ihrer Fruchtbarkeit, auf weiten Räumen die mannigfaltige Abwechselung“ zeigten, ,welche allen Kulturlandschaften eigen“ (von Roon, 1838: S. 315) sei. „Kulturboden“ wird hier offenkundig weitgehend synonym mit „Kulturlandschaft" gebraucht, ebenso die im Umfeld des Zitates auftauchenden Begriffe „Kulturfläche“ (S. 313) und „Kulturland“ (S. 314) sowie an anderer Stelle der Begriff des „Fruchtbodens" (S. 257).

In all diesen Begriffsvarianten steckt die anbauende landwirtschaftliche, die materielle Tätigkeit des Menschen, doch ist damals auch schon von „deutschem Boden“ die Rede, so beim schon zitierten Mendelssohn, doch ist mit der Kontrastierung, dass er ,einen entschieden abweichenden Charakter von der des westlichen Nachbarlandes" (Mendelssohn, 1836: S. 115) trage, noch keine ethnische Wertung verbunden. Es geht Mendelssohn allein um die ,auffallende Eigenthümlichkeit“ des Reliefs ,,andern Ländern, z.B. Frankreich oder England gegenüber" (S. 120). Die Kulturzustände zwischen einzelnen Völkern, die Mendelssohn (s.o.) anspricht und nach hoch/höher und tief/tiefer bewertet (z.B. S. 263 u. S. 413), macht er aber nicht an unveränderlichen Wesensmerkmalen der Völker fest, sondern, wie zwischen Russen und Nord-Amerikanern (s.o.), an gesellschaftlichen Zuständen (S. 474).

Allerdings wurde schon in der Startphase der modernen Geographie ein enger Zusammenhang zwischen der „Cultur der Einwohner“ eines Landes und der „Cultur des Bodens“ sowie der „Gesammtcultur des Landes“ dergestalt hergestellt, dass eine Veränderung des Kulturzustandes der Bewohner sich auch auf das Land „veredeln[d]“ oder „verschlimmern[d]“ auswirken müsse: „Sinkt die Cultur der Einwohner, werden die Menschen in einem Lande, weichlich, schlaff, träge, dumm etc. so verwildern die angebauten Fel- der wieder, Straßen und Canäle verfallen, Gebäude stürzen ein, ganze Städte sinken in Ruinen u.s.w." (Henning, 1812: S. 303f.). Der Schluss, dass sich die Kulturhöhe der Völker auch im Landschaftsbild spiegelt, gehört zur Grundeinsicht der länderkundlichen Geographie, er war ihr paradigmatischer Kern. Wie das Land, so das Volk, wie das Volk, so das Land, lautete die Devise ihrer Vertreter seit Beginn des 19. Jahrhunderts (vgl. Schultz, 2015, S. 176ff.).

Um 1900 sind beide Begriffe, „Volksboden“ wie „Kulturboden“, im Zusammenhang mit den österreichischen Nationalitätenkämpfen und der Agitation der alldeutschen Publizistik als „politisch aufgeladene Schlagwörter“ fest in den völkisch-nationalen Diskursen verankert, wurden allerdings „,noch in keinem gemeinsamen Konzept konkret aufeinander bezogen" (Henniges, 2015: S. 1314).

Unter dem Titel „Die Besiedlung des deutschen Volksbodens“, verfasst vom Vorsitzenden des Alldeutschen Verbandes, Ernst Hasse, erschien 1905 ein Heft zur „Heimatpolitik", das diese Politisierung als expansionistische Programmatik offen zum Ausdruck brachte. Hasse, der von sich selbst sagt, er sei „weder Geschichtsschreiber, noch Geograph, noch Ethnograph", sah es als seine Aufgabe an, die Bedeutung des Volksbodens als ,die Grundlage unseres staatlichen Daseins“ in der „Gesamtheit“ aller Einzeltatsachen zu würdigen, was dem deutschen „Volksbewußtsein“ bislang noch fehle. Historiker, Geographen und Ethnographen, darunter Friedrich Ratzel (ebenfalls Mitglied des Alldeutschen Verbandes) werden von Hasse aufgerufen, an einem Überblick der ,riesenhaften Literatur“ zum Thema mitzuwirken, um „etwas [zu] schaffen, was auf der Höhe der deutschen Wissenschaft stände" (Hasse, 1905: S. 1f.). Im Schlusskapitel forderte Hasse, dass „die Eindeutschung der undeutschen Grenzmarken“ erst dann ,zum Stillstand gelangen“" dürfe, wenn es gelungen sei, ,den deutschen Volksboden mit den Grenzen des deutschen Reichs in Uebereinstimmung zu bringen, alle noch fremdvölkisch besiedelten Reste des Deutschen Reiches einzudeutschen und dem ausdehnungsbedürftigen deutschen Volke nach dem Maße seiner Ausdehnungskraft und Ausdehnungslust neuen Volksboden zur Verfügung zu stellen“ (S. 125). Das war ein uferloses Programm! Kannte es Penck?

Einen ersten Anstoß zur Deutschtumsarbeit, berichtet Penck, habe er schon als Student bei einem Pragaufenthalt erhalten. Dabei habe er die Erfahrung gemacht, dass Klagen über die Unterdrückung des Deutschtums nur noch mündlich weitergeben wurden statt per Post, was ihm ,ein Wink fürs Leben“ gewesen sei. Wer, wie er, in Österreich länger gelebt habe, der wisse, ,,wie systematisch dort alle deutschen Regungen unterdrückt" (Penck, 1930/31: S. 512) worden seien. Später, in seiner Zeit als Hochschullehrer in Wien, haben ihn auch die Forschungen seiner Schüler, darunter vor allem Hanslik mit seinen Arbeiten, mit ethnopolitischen Diskursen vertraut gemacht (Henniges, 2015: S. 1317ff.).

Schriftlich äußerte sich Penck erstmals ausführlicher zu Deutschtumsfragen 1907 in einem Aufsatz mit dem Titel 
Deutsches Volk und deutsche Erde. Seine Ausführungen sind ein einziges Klagelied über den weltweiten Rückzug des Deutschtums. Besonders störte ihn, dass die Deutschen im Reich, „gleichgültig“ zusähen, „,wie bei den peripherisch wohnenden Deutschen Sprachinsel auf Sprachinsel verloren“ gehe, „wie Schritt für Schritt die Sprachgrenze zu unseren Ungunsten verschoben“ (Penck, 1907: S. 180) werde. Speziell die tschechisierten, polonisierten, slawonisierten oder magyarisierten Deutschen würden für das deutsche „Weltbürgertum" verloren sein, also nicht mehr deutsche Interessen in der Welt vertreten. Daher sei es ,nicht bloß eine nationale Pflicht, sondern auch ein Gebot des Humanismus, das Auslanddeutschtum zu schützen“ (S. 181f.). Für die in den Städten lebenden Deutschen sei dies nur schwer möglich, darum konzentrierte sich Penck auf den „deutschen Bauern“, der an alter Art und Sitte und an seiner deutschen Sprache festhielt: „Faßt das Deutschtum Wurzeln, gesellt sich zum deutschen Volkstum seine Erde, so ist es lebenskräftig für lange Zeiten“ (S. 182). Hier hätte nun das Begriffspaar „Volks- und Kulturboden“ einspringen können, doch taucht im Text nur der Begriff des ,Sprachbodens“ auf, ohne besonders herausgestellt zu werden.

Im Krieg stürzte sich Penck dann verstärkt in die bisher von ihm vernachlässigte Politische Geographie, doch trotz mancher Anklänge an Ratzel, etwa durch Übernahme des Lebensraum-Begriffs oder die Auffassung, dass die natürlichen Räume dem Wachstum der Staaten angepasst werden müssten (s.o.), entwickelte Penck seine Vorstellungen nicht am Schreibtisch, sondern nach Art des im Gelände arbeitenden Geomorphologen beobachtend im Feld. Nicht Bücher, sondern das Auge lieferte ihm die Belege für seine Theorien. So auch als Mitbegründer auf einer Reise der Landeskundlichen Kommission beim Generalgouvernement Warschau im Mai 1916 in die okkupierten Gebiete in Russisch-Polen. Nur wenige Tage reichten ihm, um durch Augenscheinnahme sein ethnopolitisch-geographisches Weltbild nach einem stereotypen, dichotomischen Beschreibungsschema zu formatieren (Henniges, 2015: S. 1315f. u. 1326f.).

Zwei Welten, auch dieses Motiv übrigens schon bei Ratzel (1898: S. 304) angelegt, stießen Penck zufolge im Osten schroff aufeinander, eine Welt der Ordnung und eine Welt der Unordnung. Auf der Ordnungsseite fand er saubere, freundliche und ansehnliche Siedlungen mit einem reichbebauten Boden, auf der Seite der Unordnung erbärmliche, schmutzige, unscheinbare Häuser und ein verwahrlostes Land. Auch die Menschen wurden diesem Wertungsschema unterworfen. Nur wo Ordnung herrschte, da zeigten sie sich Penck geistig beweglich, arbeitsam und tüchtig, vor allem aber als gelehrige Schüler der Deutschen. Selten nur attestierte Penck nicht-deutschen Völkern, aus eigenem Antrieb etwas Ordentliches geleistet zu haben, einigen bescheinigte er, über einen guten Kern zu verfügen, der entwicklungsfähig sei, immer aber galt als Maßstab der Beurteilung der Entwicklungsstand bei ,uns“. Das war gegen Ende des Weltkriegs Pencks Weltbild, auf das er später immer wieder zurückgriff. Aus sei- nen subjektiven (Vor-)Urteilen wurden objektive Merkmale, doch fehlte vom Doppelbegriff des ,Volks- und Kulturbodens“, der solche Unterscheidungen stützte, weiterhin jede Spur. Nur beiläufig tauchte der „deutsche Volksboden“ (Penck, 1918b: S. 127) auf.

Der Endstand der terminologischen Entwicklung ging aus Aktivitäten von Wissenschaftlern, Deutschtumsfunktionären und Politikern seit Beginn der 1920er hervor, die sich neben der Suche nach institutionellen Möglichkeiten, Forschungen zum Grenz- und Auslandsdeutschtum anzustoßen und zu koordinieren, auch um eine begriffliche Klärung des neuen Forschungsfeldes bemühten. 1923 kam es zur Gründung der Leipziger Mittelstelle für zwischeneuropäische Fragen, die wenig später auf Initiative von Volz und Penck in Mittelstelle für Volks- und Kulturbodenforschung umbenannt wurde (Haar, 2000: S. 30). 1925 erschien dann in dem Sammelband Volk unter Völkern Pencks Aufsatz Der deutsche Volks- und Kulturboden. Beigefügt war ihm die eingangs dieses Beitrags schon erwähnte, von Penck konzipierte Schwarz-WeißKarte, die der nationalen Propaganda dienen sollte (Haar, 2000: S. 377). Außerdem gab es noch zwei von Penck entworfene farbige Versionen: eine Wandkarte (1925) und eine Handkarte (1926).

Pencks Karten regten zu unzähligen Variationen und Modifikationen an, sein Aufsatz wurde zu einem Referenztext für die Begründung der neuen interdisziplinären Forschungsrichtung (vgl. Herb, 1997: S. 55ff.). Durch diesen überwältigenden Erfolg ging unter, dass Penck stets an der politischgeographischen Seite seines Land-Volk-Denkens festhielt und sich explizit in der länderkundlichen Traditionslinie der Geographie verankerte. Auch die heutige Wissenschaftsgeschichte, scheint mir, kann mit dieser Seite Pencks wenig anfangen.

Penck bot allerdings für die Volkstumsforschung kein ausgearbeitetes Forschungsprogramm, sondern im Grunde nur weltanschaulichen Trost, der über die deutsche Kränkung durch Versailles hinweghelfen sollte. „Wo deutsches Volk siedelt, ist deutscher Volksboden, da hört man deutsche Sprache und sieht man deutsche Arbeit" (Penck, 1925: S. 62). Durch die „Tüchtigkeit“" seiner Menschen habe er ,,allenthalben ein bestimmtes, deutlich erkennbares Gepräge erhalten“" (S. 64). Die politische Brisanz scheint auf, wenn Penck die staatliche Zersplitterung der Deutschen anspricht: „Fünf Staaten erstrecken sich heute im Bereiche des deutschen Volksbodens: das Deutsche Reich, das nur Dreiviertel desselben umfaßt, Österreich, Danzig, Luxemburg und Liechtenstein. Zehn Staaten greifen in das [sic] Bereich des deutschen Volksbodens über: Dänemark, Litauen, Polen, Tschechoslowakei, Ungarn, Jugoslawien, Italien, Schweiz, Frankreich und Belgien" (S. 63).

Der deutsche Volksboden war für Penck zugleich deutscher Kulturboden, der sich markant von ,,benachbarten Kulturgebieten" abhob. Charakteristisch, erläuterte er, sei für ihn eine ,äußerst sorgfältige Bebauung“ (Penck, 1925: S. 64), die zeige, dass der Deutsche selbst dort nicht kapituliere, 
wo es schwierig werde. Nichts bleibe, wo Deutsche siedelten, ungenützt liegen, Nachlässigkeit werde nicht geduldet, und der Boden danke es mit ertragreichen Ernten. Selbst die Blumen auf den deutschen Gräbern mussten dafür herhalten, die romanischen Friedhöfe mit ihren Steinplatten zu disqualifizieren. Die kompensatorische Funktion für die Niederlage scheint auf, wenn Penck rühmend betont: „Der deutsche Kulturboden ist die größte Leistung des deutschen Volkes“ (S. 69).

Als Besonderheit des deutschen Kulturbodens hob Penck sein globales Vorkommen hervor. Ob in Brasiliens Urwäldern, an der regenreichen Westküste Chiles, im halbariden Kontinentalgebiet an der Wolga oder am Saume der Wüsten Südwest-Afrikas: „Wo immer auch Deutsche gesellig wohnen und die Erdoberfläche nutzen, tritt er [der deutsche Kulturboden] in Erscheinung“ (Penck, 1925: S. 69). Damit stellte Penck klar, dass der deutsche Kulturboden (resp. die deutsche Kulturlandschaft) nicht auf physische Faktoren und deren Zusammenwirken zurückging, sondern allein „,das Werk bestimmt veranlagter Menschen“ "war, ,die die Natur nach ihrem Willen" (S. 70) geformt hatten. So spiegelte der deutsche Kulturboden als ,das Werk deutscher Intelligenz, deutschen Fleißes und deutscher Arbeit" den Grundzug des deutschen „Wesens und Könnens“ (S. 72) wider, der unter jeglichen geographischen Verhältnissen auf der Erdoberfläche entstehen konnte. Jedermann konnte das Deutschtum am deutschen Kulturboden unmittelbar sehen, so wie einst die deutschen Soldaten im Weltkrieg. Die alt-geographische Doppelformel: Wie das Land, so das Volk, wie das Volk so das Land, war hier einseitig auf die Richtung vom Volk zum Land beschränkt. Als „Deutschland“ wollte er diese Gebiete in anderen Kontinenten jedoch nicht angesprochen wissen, auch nicht den Kulturboden des Inseldeutschtums in Europa, wie z.B. in Siebenbürgen (Penck, 1933: S. 322).

Als weitere Besonderheit des deutschen Kulturbodens befand Penck, dass auch Nicht-Deutsche ihn schaffen konnten. „Schon eine kleine Zahl von Deutschen“ habe oftmals genügt ,um ein großes Land in deutschen Kulturboden zu verwandeln“ (Penck, 1925: S. 69f.), ohne auch zum deutschen Volksboden geworden zu sein, wie die ehemaligen russischen Ostseeprovinzen, aber auch slawisch besiedelte Gebiete, speziell in Böhmen und Mähren und bis zur Weichsel, zeigten. „Eine eigene tschechische Kulturlandschaft" gebe es nicht; hier habe eine tausendjährige Zugehörigkeit zum Deutschen Reich dazu geführt, dass sich die tschechische von der deutschen Kulturlandschaft ,lediglich durch den geringeren Grad von Sauberkeit“ (S. 68) unterscheide. Im Gebiet bis zur Weichsel wiederum hätten vor der Völkerwanderung germanische Stämme gesessen und dort einen ,,altgermanischen Kulturboden“, den „lugischen“, geschaffen, der jedoch seine „voller Wertung“ erst durch die späteren deutschen Siedler erfahren habe. Diese Siedler hätten dann den in der Völkerwanderungszeit nachgerückten Slawen beigebracht, ,gleiches zu tun“ (S. 69), doch sei es zu einer völli- gen Einbeziehung des altgermanischen Kulturbodens in den deutschen nicht gekommen.

Schließlich stellte Penck dem geschlossenen deutschen Volks- und Kulturboden noch die ihm vorgelagerten kleineren und größeren Volksboden-,,Inseln“ zur Seite, ,umgeben von Kränzen deutschen Kulturbodens" (Penck, 1925: S. 66), die vor allem im Osten eine aufgelöste Grenzsituation geschaffen hätten. Hier, ,,auf der Ostseite des deutschen Volksbodens", liege schon aufgrund des Ineinandergekeiltseins von Deutschen und Slawen „die große Schwierigkeit der Begrenzung eines rein nationalen Deutschland“" (S. 62).

Nach 1933 diente Penck seine Volks- und KulturbodenIdeologie dem neuen Regime als „nationale Erdkunde“ an. Sie sollte der Jugend die deutsche Geschichte als Geschichte eines arbeitsamen, schaffensfreudigen Heldenvolkes präsentieren nach dem Motto: „Gott schuf den Raum und wir machten Deutschland daraus“" (Penck, 1934a: S. 260). Zwar fülle das deutsche Volk ,den deutschen geographischen Raum“ (Penck, 1933: S. 323) nicht völlig aus, habe aber als ,arbeitendes, schaffensfreudige Volk" seine natürlichen Gegebenheiten zu einem „einzigartigen deutschen Kulturboden“ (S. 335) gemacht, der sich klar von Kulturlandschaften im Süden und Westen abhebe, die eine ,gealterte Kulturlandschaft“ zeigten, „die nicht so leistungsfähig“" sei ,wie die deutsche, ausgereifte" (S. 327). Immerhin gestand Penck für das deutsche Volk den früheren Kulturtransfer aus dem Süden und Westen ein, doch befand er anmaßend und überheblich, dem Osten habe es immer nur gegeben, so wie es der ganzen Welt wie kein anderes Volk Dichter und Denker, Entdecker und Erfinder gegeben habe. Ein solches „Weltbürgertum" sei als Erziehungsziel nur noch zu akzeptieren, wenn es „fest im eigenen Volke“ (S. 332) wurzele.

Aber nicht erst ab 1933, von Anfang an verstand Penck die Kulturgeographie als ein volkspädagogisches Projekt, das durch entsprechende Erziehung der Jugend das Wiedererstarken Deutschlands einleiten sollte! Schon 1921, bevor er den Volks- und den Kulturbodenbegriff zum Doppelbegriff zusammenzog, riet er dem preußischen Kultusministerium, im Geographieunterricht die Erdoberfläche nicht als Schauplatz geschichtlicher Vorgänge, sondern „,der menschlichen Arbeit" behandeln zu lassen, damit der Schüler sehe, wie weit der „grösste Kampf“ die Menschheit, ihr Kampf mit der Natur, ,an einer bestimmten Stelle gediehen“ sei, um „einen besseren Massstab für die Arbeit der einzelnen Völker auf der Erde“ zu erhalten, was „durch blosse Würdigung ihrer politischen oder ihrer in Ein- und Ausfuhrzahlen sich spiegelnde wirtschaftliche Stärke" nicht erreicht werden könne. „Gerade in der gegenwärtigen Zeit" bedürfe das deutsche Volk ,etwas, an dem es sich erheben (...) und aufrichten“" (Penck, 1921: Blatt 229) könne. In seinem späteren Volksund Kulturbodenaufsatz bekräftigte er, dass ein Nationalgefühl nur durch das Beispiel einer ,uneingeschränkt großen Leistung " anerzogen werden könne, einer Leistung, wie sie „in der Schaffung eines deutschen Kulturbodens“ (Penck, 1925: S. 72) vorliege. 
In den Erdkundeschulbüchern der Weimarer Republik fand Pencks Gedankenwelt - inklusive der einschlägigen Karten - breiten Eingang (vgl. Schultz, 2011: S. 130ff.). Es ist schwer vorstellbar, dass bei entsprechender Agitation durch die Lehrer bei den Schülern nicht, wie diffus auch immer, der Eindruck entstehen musste, im Osten seien die Grenzen im „Kampf der Völker“ um Lebensraum politisch noch nicht ausgekämpft. Warum sollte der im Kartenbild weit sich öffnende Wirkungs- und Einflussraum der Deutschen im Osten, der vom Finnischen Meerbusen bis zum Schwarze Meer ging und darüber hinaus deutsche Volkstumsinseln bis zur Krim, zur unteren Wolga und zum Kaukasus zeigte, nicht eines Tages für das Deutsche Reich, in welcher Form auch immer, politisch wiederbelebt werden können? Jedenfalls legten ihnen Schulbücher, Wandkarten und geopolitische Kartenskizzen in suggestiver Form nahe, dass speziell im Osten die deutschen Grenzen lediglich das Momentbild einer langen, noch unabgeschlossenen Entwicklung waren (Henniges und Meyer, 2016).

\section{Land im Osten für ein Volk ohne Raum?}

War aber den Beteiligten auch klar, dass sie damit einem Anwendungszusammenhang in die Hände arbeiteten, der brutale Konsequenzen bis hin zum Völkermord einschloss? Und wenn nicht, trugen sie dann gleichwohl eine Mitverantwortung für die spätere Umsiedlungs-, Deportations- und Mordpolitik der Nazis, weil sie mit der teils klaren, teils diffusen Volks- und Kulturbodentheorie die Wertungen geliefert und die Stimmung erzeugt hatten, die die Grundlage für die Akzeptanz einer solchen Politik abgaben?

Penck dachte sowohl in Bezug auf das Deutsche Reich als auch das deutsche Volk machtpolitisch. Seinen schon zitierten Aufsatz von 1907 leitete er mit der stolzen Feststellung ein: „Mächtig wie niemals zuvor ist das Deutsche Reich, kräftiger denn je das deutsche Volk“, und das sei nicht durch „Waffengewalt" erreicht worden, ,sondern durch friedliche Arbeit“. „Uneingeschränkt" sei ,die Anerkennung, die ihm für wissenschaftliche und technische Leistungen, für die Beteiligung am Weltverkehr gezollt“ (Penck, 1907: S. 179) werde. Ethnopolitisch habe das Reich jedoch zur Aufrechterhaltung seiner ,achtunggebietenden Stellung“ (S. 179) auf allen Seiten zu kämpfen, denn seitdem ,der einzelne Deutsche“ im Gegensatz zum früheren zersplitterten Deutschland „Glied eines mächtigen Volkes" sei, werde er von anderen gefürchtet mit der Folge, dass Deutsche um der ,wirtschaftlichen Vorteile" (S. 180) wegen nur noch willkommen seien, wenn sie ihr Deutschtum aufgäben. Damit schwächten sie natürlich auch Deutschlands Machtstellung. Denn die Macht eines Staates, so dachten mit Penck damals viele, hänge von der Menge seiner Bevölkerung ab und somit zugleich von der ihm zur Verfügung stehenden Menge an Land (vgl. Ratzel, 1903: S. 423ff.). Wollte ein Machtstaat sich als Machtstaat unter Machtstaaten behaupten oder seine Position in der
Rangfolge dieser Staaten verbessern, so musste er dafür sorgen, dass seine Menschen möglichst nicht ins Ausland abwanderten, um dort als der sprichwörtliche „Kulturdünger“ zu dienen.

Mit dem Weltkrieg waren diese Probleme für Penck zu einer Existenzfrage des Deutschtums eskaliert, denn es bestand für ihn „kein Zweifel mehr: der große Krieg ist ein Krieg gegen das Deutschtum überhaupt“ (Penck, 1915b: S. 9). „Eng und klein“ sei „die Fläche, welche uns Deutschen auf der Erde zur Verfügung“ (S. 9) stehe, doch: „Ein wachsendes Volk braucht Raum" (S. 10). Zwei Fragen beschäftigten Penck daher im zweiten Kriegsjahr brennend. Erstens: „Soll Deutschland in Zukunft das verderbliche Zwei-Kindersystem aufgreifen und wie Frankreich auf den natürlichen Zuwachs seiner Bevölkerung verzichten?“ (S. 10). Und zweitens: „Soll es fortfahren, den Überschuss seiner Bevölkerung abzugeben an das Ausland, das ihn aufschluckt und seinem Volkstum gewaltsam entfremdet, wie es die Gegenwart lehrt?“ (S. 10). Auf diese beiden ,großen Fragen für die Zukunft des deutschen Volkstums“" gab es für Penck ,,aus nationalen Gründen“ nur ein „entschiedenes Nein“; die „richtige Lösung des Bevölkerungsproblems“ liege vielmehr ,auf politischgeographischem Gebiete“" (S. 10).

So war die Bevölkerungsfrage zur Raumfrage und die Raumfrage zur Frage nach den deutschen Kriegszielen geworden, denn innerhalb der eigenen Grenzen sah Penck kaum noch Platz, und auch rings um die deutschen Grenzen herum sei der Raum ,weggegeben, stellenweise dicht besiedelt" (Penck, 1915b: S. 10). Wo also war ,leerer" Raum zu haben? „Der Krieg“, freute sich Penck, habe ihn „geschaffen" (S. 10). Mit der russischen Armee hätten sich auch Litauer und Letten zurückziehen müssen, um dem vorrückenden deutschen Heer ,ein menschenleeres, daher unwirtliches Land zu überlassen" (S. 10); Russland denke aber nicht daran, sie zurückkehren zu lassen, ihr Wohngebiet werde künftig Sibirien sein. Sollten aber Litauen und Kurland bei Russland bleiben, so würden dort Russen einziehen. Dann würde das Deutsche Reich nicht nur auf Russland, sondern auf ,echtes Russentum“ stoßen, was „unter allen Umständen vermieden werden“ "S. 11) müsse. Somit stand für Penck fest, wie er seinem Freund Partsch am Neujahrstag 1916 brieflich erläuterte, dass er „die natürliche Westgrenze Russland“, die er vom Peipussee zum Dnjepr gezogen habe (s.o.), nicht zugleich als die Grenze des Deutschen Reiches betrachte. Vielmehr wünsche er sich ,die deutschen Grenzen so wenig als möglich“ hinausgeschoben, ,am ehesten gegen Kurland“, während Satellitenstaaten ,mit eigener innerer Verwaltung und starker deutscher Beeinflussung " (Albrecht Penck, pers. Mitteilung, 1916, zit. n. Brogiato und Schellhaas, 2014: S. 364) das Deutsche Reich und Russland auseinander halten sollten.

Mit der Niederlage waren solche Träume vorerst ausgeträumt, doch statt die Friedensregelung z.B. an jenen Regelungen zu messen, die man selbst in Brest-Litowsk gegenüber Russland durchgesetzt hatte, pochte man auf Wilsons Selbstbestimmungsrecht der Völker, das mit dem Siegerrecht 
kollidierte, das man selbst praktiziert hatte. Vor allem an der Ostgrenze war dies ein großes Problem. Mit dem Mythos der so genannten Ostkolonisation, der im 18. Jahrhundert im Gefolge der Aufteilung Polens erfunden worden war, tröstete man sich über die traurige Gegenwart hinweg und träumte für die Zukunft von einem neuerlichen deutschen Machtund Einflussraum im Osten. Das Deutsche Reich, so redete man sich stark, werde nach einer vorübergehenden Schwächephase in einem zweiten Anlauf erst als Großmacht auf die europäische, dann als Weltmacht auf die Weltbühne zurückkehren.

Pencks Volks- und Kulturboden-Theorie eröffnete solchen neuen Träumen die Wege. Was als Paradigmenbruch erscheint, war keiner, denn die Fugen des Mensch-NaturVerhältnisses, die rhetorisch aufgerissen wurden, konnten leicht wieder geschlossen werden. Je nachdem, welche Seite des Mensch-Natur-Verhältnisses gerade in den öffentlichen Diskursen angesagt war, konnte der Geograph sich darauf einstellen: sich entweder mehr auf die Seite der Natur oder mehr auf die Seite des Menschen schlagen oder sich irgendwo dazwischen positionieren. Penck hat mit dieser Möglichkeit virtuos ein raumbegriffliches Doppelspiel inszeniert. Durch den kategorial weiträumig ausgreifenden politischgeographischen Unterbau seines ethnopolitischen Denkens verlieh er den revisionistischen Wunschträumen in Richtung Osten Adlerflügel. Wie weit reichten seine konkreten territorialen Vorstellungen?

Was Polen anging, glaubte Penck noch kurz vor dem Kriegsende daran, dass es diesem gelingen werde, sich „ohne das Bleigewicht Litauens und Weißrußlands an seinen Füßen (...) so gedeihlich zu entwickeln“, dass es nicht nur durch „Natur und Bodenbeschaffenheit auf das innigste mit dem germanischen Mitteleuropa“ verknüpft sei, sondern auch kulturell ,ein Stück echten mitteleuropäischen Bodens“ werde, während es aktuell nur als ,Zwischenland“ erscheine, weil der „,hohe kulturgeographische Gegensatz“ (Penck, 1918b: S. 131) seine Zugehörigkeit zu Mitteleuropa noch verschleiere. Hoffnung machte ihm, dass nach Ansicht seines Schülers Hanslik die Kulturgrenze des altpolnischen Reiches innerhalb des Deutschen Reiches im Schwinden begriffen sei, so dass Gleiches auch ,,an der Grenze von Kongreßpolen“ (S. 131) erwartet werden könne.

Nachdem sich das neue Polen nicht bescheiden an den von der Natur vorgeschriebenen geographischen Verhältnissen orientierte, die ihm von Penck zugestanden wurden, kam er nicht mehr auf die Entwicklungsfähigkeit des polnischen Volkes zurück und schloss sich wieder der Geringschätzung der slawischen Völker an, die seit Mitte des 19. Jahrhunderts in zahlreichen deutschen Schriften grassierte. Für ihre Verfasser war der slawische Osten Europas ein heruntergekommener, verwahrloster Raum, der durch seine mehr schlecht als recht vor sich hinlebende Bevölkerung niemals in eine blühende Landschaft verwandelt werden würde. Gehörten solche passiven, unschöpferischen Völker (vgl. Schultz, 2015, S. 180ff.) überhaupt hierher, wo ihnen doch ganz of- fensichtlich jene kulturlandschaftsbildende Kraft der Deutschen fehlte, die gebraucht würde, um aus dem östlichen Mitteleuropa ein echtes Mitteleuropa zu machen, ja, die zum Teil noch sich selbst der Natur und die Natur sich selbst überließen?

Ein solches antislawisches Weltbild im ,Daseinskampf der Völker" vertraten freilich auch andere Geographen, nicht nur Penck. In Termini der Küstenmorphologie beklagte Joseph Partsch 1906 zeitgleich mit Pencks Klage über den Rückgang des Deutschtums auf der Welt (s.o.) den „Ansturm der slawischen Völkerwogen gegen den Besitzstand deutschen Volkstums“ und forderte dazu auf, ,mit scharfer Aufmerksamkeit den Ufersaum im Auge zu behalten, um nicht durch Landverluste überrascht zu werden“ (Partsch, 1906: S. 4). Schon sei die „schöpferische Lebenskraft“ der slawisch umfassten deutschen Städte Oberschlesiens bedrängt und bedroht, und auch ,der deutsche Besitz an schlesischem Boden“ erleide „neuerdings einen Abbruch“ (S. 4). In seiner Ansprache zur Eröffnung des 21. Deutschen Geographentages 1925 in Breslau rüttelte Philippson in fast apokalyptischen Tönen seine Zuhörer wach: „Und dieses alte Zentrum deutscher Kultur und Geschichte [Breslau] steht auf vorgeschobenem Posten der Ostmark, als ein Fanal deutscher Bildung und Kraft, umbrandet von den gierigen Wellen des Slaventums!“" (Philippson, 1926: S. 26).

Immerhin räumte auch Philippson, wie einst Penck (s.o.), Polen eine, wenngleich nur schwache, geographische Existenzberechtigung ein, auf keinen Fall aber in seinem gegenwärtigen Grenzumriss. Als natürliche Einheit umfasse Polen nur ,die Stromgebiete der Weichsel oberhalb des Knies bei Thorn (Russisch-Polen und Westgalizien) und das der Warthe etwa bis zur Vereinigung mit der Netze (preußische Provinz Posen).“ Das sei ,das Land, welches allein wir geographisch und national als Polen anerkennen können“ (Philippson, 1928: S. 78). Dieses Polen, das seine neue politische Existenz den deutschen Siegen im Osten verdanke (ohne den Deutschen dankbar zu sein), gehöre zu Mitteleuropa und habe seine Kultur „von Westen, von den Deutschen“ (S. 79) erhalten.

\section{Abschließende Reflexionen zur Anklage Pencks}

Nach dieser Sichtung einschlägiger Arbeiten Pencks will ich abschließend eine Antwort auf die Frage versuchen, inwieweit die Anklage, Penck gehöre zu den Mittätern am Völkermord der Nationalsozialisten, berechtigt ist. Hat er, wie auch der Historiker Ingo Haar im Handbuch der völkischen Wissenschaften meint, jenen völkischen Wissenschaftlern zugearbeitet, deren ,bevölkerungspolitisches Szenario (...) die expansionistische und rassistische Grundlage der Groß- und Lebensraumpolitik des ,Dritten Reiches“" (Haar, 2008: S. 380) antizipiert habe? Oder trifft eher Burkerts vorsichtigeres Urteil zu, dass Pencks Vorstellungen über den offiziellen Revisionismus der Weimarer Republik hinausgin- 
gen, aber hinter den Vorstellungen der Nationalsozialisten zurückblieben (Burkert, 2000: S. 590)?

Tatsächlich hielt sich Penck bezüglich der staatsrechtlichen Konsequenzen seines fragwürdigen Volks- und Kulturbodenkonzepts zurück, (fast) alles ließ er in der Schwebe, eine Aufforderung zur politischen Aktion mit konkreten territorial- und bevölkerungspolitischen Empfehlungen vermied er in seinen Schriften. Stattdessen erklärte er: „Von vornherein ist der Begriff Deutschland ein unpolitischer", der dem „Volksbewußtsein“ (Penck, 1933: S. 323f.) entspringe. War Pencks Deutschlandbegriff damit wirklich politisch harmlos? Keinesfalls, denn „unpolitisch“ bedeutete für ihn lediglich, dass der ethnographische wie der geographische Deutschlandbegriff Gebiete umfasste, die nicht mit dem aktuellen staatsrechtlichen Begriff des Deutschen Reiches zusammenfielen. In jedem Bedauern, dass dies nicht der Fall sei, lag als emotionaler Unterstrom der Wunsch nach mehr Deckung der drei Kategorien. Was nicht war, konnte ja noch werden, was nicht mehr war, wieder werden. Schrie nicht ,der deutsche Kulturboden in Pomerellen“, der laut Penck (1933: S. 327) nach dem Exodus von Deutschen „schon verwahrlost[e]“, geradezu nach Revision? Wie provozierend musste es erscheinen, wenn man den Völkern der Nachbarstaaten zumutete, sie siedelten und lebten, obgleich staatlich anders verfasst, in Deutschland, Deutschland im Sinne der Kulturbodenkategorie?

Immerhin: Die Schweiz, die ja auch zu einem erheblichen Teil deutscher Volks- und Kulturboden war, stand für Penck nicht zur Disposition, die Niederlande sowie der flämische Teil Belgiens wurden von ihm in der Schwarz-Weiß Karte überhaupt nicht in eine Beziehung zum Volks- und Kulturboden-Deutschland gebracht und in den beiden farbigen Karten, der Wand- und Handkarte, lediglich als Gebiete der niederdeutschen Sprache ausgewiesen. Auch schwebte ihm keine „geopolitische Restitution“ (Haar, 2008: S. 380) Österreich-Ungarns vor, von der einige völkische Wissenschaftler wohl noch träumten.

Völlig abwegig wäre es gar, wollte man Penck unterstellen, im Osten auch Gebiete bis zur Wolga, Kaukasien, die Krim, Bessarabien und Wolhynien als Teile eines künftigen deutschen Staates anzusehen, weil hier, kartographisch dokumentiert, ein Streuinseldeutschtum existierte. Sein politisches Wunsch-Deutschland umfasste im Wesentlichen den „geschlossenen Volks- und Kulturboden“ in Mitteleuropa. $\mathrm{Ob}$ und welche Gebiete des deutschen Kulturbodens auch ohne oder nur mit einer sehr geringen Anzahl deutscher Bewohner dazugehören sollten, ließ sich Penck nicht entlocken.

Das Volks-und Kulturbodenkonzept entstand als nichtrassistisches Konzept im biologischen Sinne. Zwar griff Penck nach 1933 auch den Rassenbegriff auf. So verwies er warnend darauf, dass ,germanisches oder deutsches Blut, sobald es sich mit fremdem mischte oder nur fremde Sprache annahm, uns feindlich wurde" (Penck, 1933: S. 328). Auch sah er die Umgestaltung der Natur- in eine Kulturlandschaft abhängig vom „Können“ und von der „Rasse“ des Menschen
(Penck, 1934a: S. 262). Doch blieb es bei solchen eher beiläufigen Anbiederungen an das NS-Regime. Privat äußerte er hingegen im September 1933, dass es „nicht so sehr auf die Rasse“ ankomme, wie vielfach jetzt gelehrt“ werde, ,sondern auf den Geist, der im Körper“ wohne. „Tüchtige Menschen“ dürfe man ,nicht gering achten, weil sie von Juden abstammen oder Juden sind“. Hier liege ,ein grundsätzlicher Fehler in der neuen Bewegung", an der ihn ansonsten vieles freue, was sie anstrebe (zit. n. Henniges, 2015: S. 1342).

Eine andere Sache ist es, dass Penck mit seinem Volksund Kulturbodenkonzept einen nationalen Kulturdünkel bediente. Im Bild der Kulturlandschaft erkannte der auf Beobachtung trainierte Geograph die Möglichkeiten und Grenzen der Völker bei der Gestaltung ihres Lebensraumes. Deswegen war ihm ,die Kulturlandschaft ein Kennzeichen der Kulturhöhe" (Penck, 1933: S. 331). Kombinierte man diese Wertung mit der weit verbreiteten Auffassung, dass nur dasjenige Volk sein Land zu Recht besaß, das es auch ordentlich bebaute, so mussten die Weiten des Ostens als quasi herrenloses Land der Zukunft erscheinen, über dessen endgültiges Schicksal das letzte Wort noch nicht gesprochen war.

Zusätzliche Schubkraft gewann das Bild vom lockenden Lebensraum im Osten, der nur darauf zu warten schien, unter den deutschen Pflug genommen zu werden, durch Verknüpfung mit dem Volk-ohne-Raum-Motiv, das Penck bereits im Ersten Weltkrieg zur Rechtfertigung von Annexionen diente, wenngleich bei weitem nicht in alldeutschen Dimensionen. Denn wenn die slawische Bevölkerung allein schon aufgrund ihrer geringen Zahl diesen Raum nicht zu füllen und zu kultivieren vermochte, so drängte sich unweigerlich der Schluss auf, dass ein so genanntes Leistungsvolk, wie das deutsche, dem es angeblich an Raum zu seiner Entwicklung fehlte, einen natürlichen Anspruch darauf hatte, sich diesen Raum zu Lasten der dort lebenden Bevölkerung kolonisierend anzueignen. Die bösen Folgen dieser Logik sind bekannt.

Allerdings hat Penck in seinen Schriften solche Konsequenzen weder offen noch andeutungsweise einkalkuliert. Auch nahm er in keiner der Schriften zu den ausgreifenden Raumphantasien anderer völkischer Wissenschaftler und Publizisten Stellung. Wohl aber haben seine politischgeographischen und ethnopolitischen Raumbilder dazu beigetragen, den Osten und Südosten Europas wie selbstverständlich als Experimentierfeld der deutschen Revisionspolitik und über diese hinaus wahrzunehmen und die ideologischen Nachfahren der früheren „Ostreiter“ in der Auffassung zu stärken, der vermeintlichen slawischen Unkultur die Segnungen deutscher Kultur und Ordnung bringen zu müssen.

Auszugehen ist davon, dass Penck auch nach dem verlorenen Weltkrieg seine Kriegszielvorstellungen aus der Kriegszeit weiter fest im Blick behielt: die Wiedergewinnung der Kolonien und die Zurückdrängung Russlands hinter eine Linie vom Weißen Meer und Finnischen Meerbusen bis zur Krim, die teilweise mit der Unabhängigkeit Finnlands und der Gründung der baltischen Staaten und Polens nach dem Weltkrieg realisiert worden war, nur eben nicht so, wie sich 
Penck dies vorgestellt hatte: mit dem Deutschen Reich als unangefochtener Ordnungs- und Hegemonialmacht in der Mitte Europas. Die Aussiedlung von „Fremdvölkern“ war für ihn jedenfalls (s.o.) kein grundsätzliches Hindernis für seine territorialpolitischen Vorstellungen. Dass am Ende einer radikalen geo- und ethnopolitisch motivierten Politik im Tarnmantel vermeintlich strenger Wissenschaft die Massenvernichtung von Menschen, der Völkermord, stehen würde, wollte er, scheint es, nicht sehen.

Dieses Nichtsehen-Wollen oder Wegblenden lässt sich allerdings vom Nichtsehen-Können, einer professionellen Blindheit, nicht scharf trennen. Um Letzteres auszuloten, muss auf Pencks naturwissenschaftlichen Habitus zurückgegangen werden, der ihn auch Politik, Wirtschaft und Gesellschaft, soweit der Geograph mit ihnen zu tun hatte, als gesteuert von Naturgesetzen verstehen ließ: „Die Freiheit des menschlichen Willens gleicht der Freiheit der einzelnen unter dem Gesetze. Auch sie steht unter den Gesetzen der mechanischen Kausalität, welche uneingeschränkt über die Massen herrschen, aber nicht in dem Einzelfalle klar zu erkennen sind“" (Penck, 1928: S. 38). Die Massen, d.h. die Völker, sind gesetzlich dazu verdammt, einen nie aufhörenden „Kampf um Lebensraum“ zu führen, auch wenn ihnen dies selbst nicht ständig bewusst ist. Aufgabe des Geographen ist es, über den Stand dieses Kampfes aufzuklären, wie er sich ihm im Bilde der Kulturlandschaft offenbart, und die Gesetze auszusprechen, die ihn steuern. Die Erkenntnis, dass das Mensch-Natur-Verhältnis ein innergesellschaftliches ist, war ihm wie allen Geographen, die am klassischen Paradigma hingen, verbaut.

Bemerkenswert ist in diesem Zusammenhang überdies, dass sich Penck von der Geopolitik deutlich absetzte, weil sie ihm die naturwissenschaftlichen Grundlagen der Geographie zu sehr zu vernachlässigen schien. Die Erdoberfläche, mit welcher der Geograph es zu tun hatte, blieb für ihn das Dauernde im geschichtlichen Wandel, die dem Menschen bei allem Spielraum, den sie ihm ließ, ,vielfach zwangsläufig“ (Penck, 1934b: S. 26) zeigte, was zu tun und was zu lassen war. Auf sie musste der Geograph stets alles rückbeziehen. Unter diesen Umständen spielen Fragen der Verantwortung keine Rolle, solange den Wegweisungen der Natur gefolgt wurde, denn die Natur hatte immer Recht. Verantwortungslos war es dagegen, diesen Gesetzen nicht zu folgen! Dass dies möglich war, setzt allerdings einen konflikthaften Dualismus von Natur und Geist voraus, der in Pencks naturwissenschaftlichem Weltbild nicht vorgesehen war. Tatsächlich funktioniert diese Art von politischer Geographie, wie sie Penck (und auch andere Geographen) praktizierten, nur, wenn die Erdoberfläche zuvor normativ aufgeladen wird, wenn in sie hineinprojiziert wird, was der Geograph als wissenschaftlich gesichertes Raumkonzept gerne verwirklicht hätte. So kehren die natürlichen Bedingungen als Vorschrift für ein bestimmtes Handeln in den politischen Diskurs zurück. Aus dem Buch der Natur wird eine Gebrauchsanweisung, die die Völker verstehen mochten oder auch nicht. Wer sie verstand, konnte damit rechnen, dass er im Rahmen der Möglichkeiten, die ihm die Natur der Länder bot, immer das Richtige tat. So ist erklärlich, dass Penck die Gebietsgewinne, die er 1917 für das Deutsche Reich reklamierte, nicht als bewusst gewollte Siegprämie im Kräftemessen der imperialistischen Mächte um ihre Weltgeltung rechtfertigte, sondern seinen Zuhörern versicherte: „Das ist kein uferloses Sehnen nach Macht, kein imperialistisches Streben. Das ist einfach Notwendigkeit" (Penck, 1917: S. 31).

Ist Penck damit entlastet? Führt seine Gefangenschaft im naturwissenschaftlichen Denken, das sich ausschließlich auf die sinnlich wahrnehmbare Erdoberfläche beschränkte und alles ausblendete, was Staat, Wirtschaft, Politik und Gesellschaft als solche betraf, dazu, dass seine Rolle als geistiger Lebensraumkrieger und Wegbereiter der NS-Politik (wenn auch nicht im radikalen, vernichtungspolitischen Sinne) relativiert werden muss? Sähe man dies so und würde man ihm Absolution erteilen, so würde man allerdings jenen Zeitgenossen Unrecht tun, die sich nicht dem Druck einer vermeintlich objektiven Wissenschaft beugten und deren revisionistische Raumphantasien übernahmen, sondern auf der Basis des Status quo der Nachkriegsordnung ein friedliches Miteinander der Völker bei garantiertem kulturellen Minderheitenschutz propagierten und den Dialog der Gewalt vorzogen. Leider waren unter den Geographen nur wenige dazu bereit.

Datenverfügbarkeit. Alle verarbeiteten Quellen sind öffentlich durch Bibliotheken, das Geheime Staatsarchiv Preußischer Kulturbesitz oder das Internet zugänglich und die ihnen entnommenen Informationen damit nachprüfbar.

Interessenkonflikt. Der Autor erklärt, dass kein Interessenkonflikt besteht.

\section{Literatur}

Aubin, H.: Zur Erforschung der deutschen Ostbewegung, Deutsches Archiv für Landes- und Volksforschung, 1, 37-70, 309331, 563-602, 1937.

Briesewitz, G.: Raum und Nation in der polnischen Westforschung 1918-1948, fibre, Osnabrück, Deutschland, 526 S., 2014.

Brogiato, H. P. und Schelhaas, B. (Hrsg.): „Die Feder versagt ...", Feldpostbriefe aus dem Ersten Weltkrieg an den Leipziger Geographie-Professor Joseph Partsch, Leipziger Universitätsverlag, Leipzig, Deutschland, 422 S., 2014.

Burkert, M.: Die Ostwissenschaften im Dritten Reich. Bd. I: 1933 1939, Harrassowitz, Wiesbaden, Deutschland, 771 S., 2000.

Etzemüller, T.: Suchen wir Schuld oder wollen wir Gesellschaft analysieren? Eine Anmerkung zur aktuellen Debatte um Hans Rothfels, Historisches Forum, 1, 27-33, 2004.

Fahlbusch, M.: Die verlorene Ehre der deutschen Geographie, Frankfurter Rundschau, 2. Oktober, S. 6, Druck- und Verlagshaus der Frankfurter Rundschau, Frankfurt am Main, Deutschland, 1999a. 
Fahlbusch, M.: Wissenschaft im Dienst der nationalsozialistischen Politik? Die „Volksdeutschen Forschungsgemeinschaften“ von 1931-1945, Nomos, Baden-Baden, Germany, 887 S., 1999b.

Haar, I.: Historiker im Nationalsozialismus. Deutsche Geschichtswissenschaft und der „Volkstumskampf“ im Osten, Vandenhoeck \& Ruprecht, Göttingen, Deutschland, S. 433, 2000.

Haar, I.: Leipziger Stiftung für deutsche Volks- und Kulturbodenforschung, in: Handbuch der völkischen Wissenschaften, Herausgeber: Haar, I. und Fahlbusch, M., Saur, München, Deutschland, 374-382, 2008.

Hasse, E.: Die Besiedelung des deutschen Volksbodens (= Deutsche Politik Bd. 1: Heimatpolitik H. 2), Lehmann, München, Deutschland, 156 S., 1905.

Henning, J. W. M.: Leitfaden beim methodischen Unterricht in der Geographie, Literarisches Büreau, Iferten, Schweiz, 567 S., 1812.

Henniges, N.: „Naturgesetze der Kultur“: Die Wiener Geographen und die Ursprünge der ,Volks- und Kulturbodentheorie“, ACME: An International E-Journal for Critical Geographies, 14, 13091351, 2015.

Henniges, N. und Meyer, P. J.: „,Das Gesamtbild des Vaterlande stets vor Augen": Hermann Haack und die Gothaer Schulkartographie vom Wilhelminischen Kaiserreich bis zum Ende des Nationalsozialismus, Zeitschrift für Geographiedidaktik, 44, 37-60, 2016.

Herb, H. G.: Under the map of Germany. Nationalism and propaganda 1918-1945, Routledge, London, UK and New York, USA, 250 S., 1997.

Herb, H. G.: Von der Grenzrevision zur Expansion: Territorialkonzepte in der Weimarer Republik, in: Welt-Räume. Geschichte, Geographie und Globalisierung seit 1900, Herausgeber: Schröder, I. und Höhler, S., Campus, Frankfurt a. M., Deutschland, 175-203, 2005.

Jureit, U.: Das Ordnen von Räumen. Territorium und Lebensraum im 19. und 20. Jahrhundert, Hamburger Edition, Hamburg, Deutschland, 445 S., 2012.

Kirchhoff, A.: Europa im Allgemeinen, in: Länderkunde des Erdteils Europa, Herausgeber: Kirchhoff, A., Temsky, Freytag, Wien, Österreich, Prag, Tschechien and Leipzig, Deutschland, 1/1, 7-87, 1887.

Kost, K.: Die Einflüsse der Geopolitik auf Forschung und Theorie der Politischen Geographie von ihren Anfängen bis 1945, Dümmler, Bonn, Deutschland, 467 S., 1988.

Mendelssohn, G. B.: Das germanische Europa, Duncker \& Humblot, Berlin, Deutschland, 502 S., 1836.

Mommsen, W. J.: Interview mit W. J. Mommsen, online aufrufbar: http://hsozkult.geschichte.hu-berlin.de/BEITRAG/intervie/ wmommsen.htm (letzter Zugriff: 19 November 2010), 1999.

Partsch, J.: Mitteleuropa, Perthes, Gotha, Deutschland, 463 S., 1904.

Partsch, J.: Von der deutschen Grenzwacht in Schlesien, Deutsche Erde, 5, 2-5, 1906.

Penck, A.: Physikalische Skizze von Mitteleuropa; Das Deutsche Reich, in: Länderkunde des Erdteils Europa, Herausgeber: Kirchhoff, A., Temsky, Freytag, Wien, Österreich, Prag, Tschechien and Leipzig, Deutschland, 1/1, 89-618, 1887.

Penck, A.: Morphologie der Erdoberfläche, Engelhorn, Stuttgart, Deutschland, Bd. 1: 471 S., Bd. 2: 696 S., 1894.

Penck, A.: Deutsches Volk und deutsche Erde, Die Woche, 9, 179182, 1907.
Penck, A.: Was wir im Kriege gewonnen und was wir verloren haben, Heymann, Berlin, Deutschland, 30 S., 1915a.

Penck, A.: Politisch-geographische Lehren des Krieges, Meereskunde, 106, 1-40, 1915b.

Penck, A.: Die Ukraina, Zeitschrift der Gesellschaft für Erdkunde zu Berlin, Bd. 1916, 345-361, 458-477, 1916a.

Penck, A.: Die österreichische Alpengrenze, Engelhorns Nachf., Stuttgart, Deutschland, 79 S., 1916b.

Penck, A.: Über politische Grenzen, Norddeutsche Verlagsanstalt, Berlin, Deutschland, 32 S., 1917.

Penck, A.: Die natürlichen Grenzen Rußlands, Meereskunde, 133, 1-40, 1918a.

Penck, A.: Polen. Eine Anzeige, Zeitschrift der Gesellschaft für Erdkunde zu Berlin, Bd. 1918, 97-131, 1918b.

Penck, A.: Die Grenzen Böhmens, Deutsche Arbeit in Österreich, 18, 177-178, 1918/19.

Penck, A.: Gutachten über einen Lehrplanentwurf von H. Wagner, Geheimes Staatsarchiv PK, Akte I. HA Rep. 76 VI Sekt. 1 Gen. ff., Nr. 2, Bd. 1, Blatt 228-231, 1921.

Penck, A.: Deutscher Volks- und Kulturboden, in: Volk unter Völkern, Bücher des Deutschtums, Herausgeber: Loesch, K. C. v., Hirt, Breslau, Polen, 1, 62-73, 1925.

Penck, A.: Deutschland als geographische Gestalt, in: Leopoldina, Quelle \& Meyer, Leipzig, Deutschland, 1, 72-81, 1926.

Penck, A.: Neuere Geographie, in: Sonderband zur Hundertjahrfeier der Gesellschaft für Erdkunde zu Berlin, Herausgeber: Haushofer, A., Selbstverlag der Zeitschrift für Erdkunde, Berlin, Deutschland, 30-56, 1928.

Penck, A.: Das Erwachen des Deutschtums, Velhagen \& Klasings Monatshefte, 45/I, 430-433, 512-515, 1930/31.

Penck, A.: Nationale Erdkunde, Zeitschrift der Gesellschaft für Erdkunde zu Berlin, Bd. 1933, 321-335, 1933.

Penck, A.: Nationale Erdkunde als Unterrichtsgegenstand, Die Deutsche Schule, 38, 257-262, 1934a.

Penck, A.: Nationale Erdkunde, Bucholz \& Weißwange, BerlinCharlottenburg, Deutschland, 36 S., 1934b.

Penck, A.: Das deutsche Kolonialproblem, Petermanns Mitteilungen, 82, 261-263, 1936.

Philippson, A.: Ansprache des Vorsitzenden des Zentralausschusses, Verhandlungen des 21. Deutschen Geographentages zu Breslau 1925, 21, 25-30, 1926.

Philippson, A.: Europa außer Deutschland, Bibliographisches Institut, Leipzig, Deutschland, 576 S., 1928.

Ratzel, F.: Deutschland, Grunow, Leipzig, Deutschland, 332 S., 1898.

Ratzel, F.: Politische Geographie oder die Geographie des Staates, des Verkehres und des Krieges, 2. Auflage, Oldenbourg, München and Berlin, Deutschland, 838 S., 1903.

Rudnyćkyj, S.: Ukraina. Land und Volk. Eine gemeinfassliche Landeskunde, Bund zur Befreiung der Ukraina, Wien, Österreich, 416 S., 1916.

Schultz, H.-D.: „Ein wachsendes Volk braucht Raum.“ Albrecht Penck als politischer Geograph, in: 1810-2010: 200 Jahre Geographie in Berlin, Herausgeber: Nitz, B., Schultz, H.-D. und Schulz, M., 2. Auflage, Selbstverlag Geographisches Institut der Humboldt Universität zu Berlin, Berlin, Deutschland, 99-153, 2011.

Schultz, H.-D.: „Jedes Volk arbeitet nach seiner Art.“ Der „Volksgeist" im Spiegel der Kulturlandschaft, in: Visuelle Geographien, 
Herausgeber: Schlottmann, A. und Miggelbrink, J., trancript, Bielefeld, Deutschland, 175-188, 2015.

Sölch, J.: Albrecht Penck, Mitteilungen der Geographischen Gesellschaft Wien, 89, 88-122, 1946.

Volz, W.: Das deutsche Land, in: Grundriß der Deutschkunde, Herausgeber: Brandt, O. H., Velhagen \& Clasing, Bielefeld and Leipzig, 1-18, 1927. von Roon, A.: Grundzüge der Erd-, Völker- und Staatenkunde 2: Physische Geographie, 2. Auflage, Duncker \& Humblot, Berlin, Deutschland, 723 S., 1838. 